Res Publica. Revista de Historia de las Ideas Políticas

ISSN: 1576-4184

http://dx.doi.org/10.5209/RPUB.56467

\title{
Audacia y precaución: Constantino Ponce de la Fuente, defensor del protestantismo
}

Christine Giesen*

Recibido: 30 de junio de 2016 / Aceptado: 10 de mayo de 2017

Resumen. Uno de los más destacados teólogos hispanos del siglo XVI, Constantino Ponce de la Fuente, fue también miembro de la comunidad protestante de Sevilla, entonces uno de los principales focos disidentes de Castilla. A diferencia de sus correligionarios exiliados, sus posibilidades literarias para dar testimonio de sus creencias eran muy limitadas, dadas las actividades inquisitoriales y censorias para contrarrestar las herejías. El artículo quiere mostrar cómo, desafiando las dificultades, Ponce consigue, sin emplear los eslóganes confesionales, exponer sus doctrinas y críticas, con audacia en ocasiones, con cautela la mayoría de las veces, valiéndose de disimulos, omisiones, insinuaciones y procedimientos legitimadores.

Palabras clave: Siglo XVI; Castilla; Reforma; protestantismo; doctrina.

\section{[en] Boldness and Precaution: Constantino Ponce de la Fuente, Defender of Protestantism}

\begin{abstract}
One of the most outstanding Hispanic theologians of the $16^{\text {th }}$ century, Constantino Ponce de la Fuente, was also member of the protestant community of Seville, then one of the main focal points of dissidents of Castile. Unlike his exiled coreligionists, his possibilities to give literary testimony of his faith were very limited due to the Inquisition's activity and censorship to stop heresy. The article aims at showing how, in spite of these difficulties, Ponce is able to explain, without using confessional slogans, his doctrines and criticism, sometimes with audacity, mostly with caution, using pretense, omission, insinuation, and legitimating procedures.
\end{abstract}

Keywords: 16th century; Castile; Reformation; Protestantism; doctrines.

Sumario: 1. Motivos y géneros literarios. 2. Lenguaje y estilo. 3. El programa reformatorio. 4. Implicaciones políticas

Cómo citar: Giesen, C. (2017). Audacia y precaución: Constantino Ponce de la Fuente, defensor del protestantismo, en Res publica 20.2, 227-241.

Se desconocen en gran parte los detalles de la formación de uno de los focos protestantes castellanos del siglo XVI, la congregación sevillana, pero se sabe que nació por obra de tres teólogos destacados, Juan Gil, llamado el doctor Egidio, y sus antiguos compañeros de estudios en Alcalá de Henares, el doctor Vargas, crítico del

Universidad Nacional de Educación a Distancia (UNED)

chrgiesen@gmx.net 
Concilio tridentino, y Constantino Ponce de la Fuente (c.1502-c.1560). El historiador eclesiástico Thomas Mc Crie, en 1829, calificó a éste último como "la mayor gloria de la Reforma española"'.

Ponce obtuvo su formación teológica en la universidad de Alcalá y completó sus estudios en el colegio de Santa María de Jesús, de Sevilla. Defensor de Erasmo, a partir de 1530 mantiene correspondencia con el filósofo de Rotterdam ${ }^{2}$. Renunciando a cargos de predicador en Cuenca y en Toledo - sus antepasados conversos tuvieron conflictos con el arzobispo Silíceo, uno de los promotores de los Estatutos de limpieza de sangre-, viene a Sevilla, tal vez por los aires de Reforma palpables en esta ciudad. En 1533 es nombrado predicador catedralicio por el Cabildo hispalense, cuyos miembros se inclinan hacia el humanismo desde hace ya tres décadas, y en el año 1546 recibe el cargo de predicador de la corte imperial en Flandes, adonde se dirige en 1548 como miembro del séquito del infante Felipe. Predica en Bruselas en 1550. Es posible que también estuviera en Inglaterra con motivo de la boda de Felipe II con María Tudor ${ }^{3}$. En 1553 vuelve a ser predicador en Sevilla, donde también se le designa profesor de teología del Colegio de la Doctrina, un orfanato con enseñanza académica, cuyo director, Fernando de San Juan, está enseñando conforme a las ideas reformistas de Constantino. Su gran reputación como "el predicador más célebre de España", en palabras de Bataillon ${ }^{4}$, se demuestra por el hecho anecdótico de que, por razones de su débil salud, se le permite beber un poco de vino en el púlpito5.

Era un hombre sumamente erudito y abierto a las corrientes humanistas europeas; se interesaba no solo por la teología sino también por la filosofía, matemáticas, derecho o medicina, hecho que se corrobora por el contenido de su amplia biblioteca ${ }^{6}$. En 1557 es nombrado canónigo magistral, desafiando las incriminaciones levantadas por el arzobispo de Sevilla y el inquisidor general Fernando Valdés acerca de presuntas herejías, irregularidades en obtener el doctorado y un supuesto matrimonio de Constantino ${ }^{7}$. Su elección es el último triunfo público de la Reforma en Sevilla ${ }^{8}$.

T. M'Crie, History of the Progress and Suppression of the Reformation in Spain in the sixteenth century, Edimburgo/Londres, William Blakwood and Sons, 1829, p. 216. Sobre la vida y obra de Ponce, cfr. también ibidem, p. 216 ss.; M. Menéndez Pelayo, Historia de los heterodoxos españoles, 3 vols., Madrid, La Editorial Católica, 1965-1967, t. II, p. 58 ss.; E. Schäfer, Sevilla und Valladolid, die evangelischen Gemeinden Spaniens im Reformationszeitalter, Halle/Saale, Verein für Reformationsgeschichte, 1903, p. 6 ss.; y E. Schäfer, Protestantismo español e inquisición en el siglo XVI, 4 vols., Alcalá de Guadaíra, Eduforma, 2014, t. I, p. 524 s., t. II, p. 412. Esta última es la versión española, traducida e introducida por Francisco Ruiz de Pablos, de Beiträge zur Geschichte des spanischen Protestantismus und der Inquisition im sechzehnten Jahrhundert, nach den Original-Akten in Madrid und Simancas bearbeitet, publicado en 1902.

2 El motivo inicial fue la respuesta de Ponce a la Dulcoratio antierasmiana de Carvajal; cf. A. G. Kinder, "Le livre et les idées réformées en Espagne", en J.-F. Gilmont, (ed.), La réforme et le livre. I'Europe de l'imprimé (1517-v. 1570), París, Les Editions du Cerf, 1990, pp. 301-326, aquí p. 313.

3 Nota de Luis de Usoz y Río, en C. Ponce de la Fuente, Suma de doctrina cristiana, Madrid, 1863, reimpreso en Barcelona, 1983, Librería de Diego Gómez Flores (es el tomo XX de la serie Reformistas Antiguos Españoles), p. 436.

4 M. Bataillon, Erasmo y España, Madrid, Fondo de Cultura Económica, 1966, p. 528.

5 T. M'Crie, op. cit., p. 219.

6 Klaus Wagner realizó un vasto estudio del inventario de la biblioteca de Ponce: K. Wagner, El doctor Constantino de la Fuente. El hombre y su biblioteca, Sevilla, Diputación Provincial, 1979; cf. las conclusiones sobre su erudición: ibidem, pp. 26 ss.

7 T. M'Crie, op. cit., pp. 220 ss.; E. Schäfer, Sevilla und Valladolid, pp. 21 ss. Otros detalles biográficos en M.-P. Aspe Ansa, Constantino Ponce de la Fuente. El hombre y su lenguaje, Madrid, Fundación Universitaria Española, 1975, pp. 31 ss.

8 "pero una victoria pírrica": E. Schäfer, op. cit., p. 22. 
F. Álvarez le define como "el representante más genuino en Sevilla del iluminismo erasmiano, que degeneró en abierto luteranismo".

En 1557, Ponce será uno de los primeros detenidos del foco protestante hispalense. Poco antes ya se han prohibido su Exposición del primer salmo de David y su Catecismo cristiano. Sabe defenderse con mucha destreza ${ }^{10}$, pero se descubren en su posesión unos escritos heréticos escondidos, entre ellos un manuscrito suyo con explicaciones de los conflictos entre las Iglesias, que iba a ser el segundo tomo de su Doctrina cristiana. Constantino niega primero la autoría de esta obra, pero acaba por confesar su fe. Se libra de la tortura, quizá a instancias del emperador ${ }^{11}$, pero muere - según rumores suicidado - después de pasar casi dos años en la cárcel de la Inquisición. Relajado en estatua, sus restos mortales y su efigie se quemarán en el auto de fe del 22 de diciembre de $1560^{12}$. Ponce es sin duda el mártir más conocido de los que se describen en las Artes de la Santa Inquisición Española, de Reinaldo de Montes ${ }^{13}$.

Es uno de los pocos protagonistas del protestantismo castellano que escribió y publicó en territorio hispano. Varias de sus obras, como las lecturas dirigidas en el Colegio de la Doctrina sobre Proverbios, Eclesiastés, el Cantar de los Cantares y el libro de Job, se han perdido ${ }^{14}$. Su escrito principal es la Suma de la doctrina cristia$n a^{15}$, que se editó en Sevilla, probablemente en 1544. Cuatro años más tarde publicó en la misma ciudad el primer tomo de una versión ampliada, inacabada, de sus conceptos teológicos, la Doctrina cristiana ${ }^{16}$. La edición más temprana conservada de la Suma es de 1551 y lleva la licencia del príncipe Felipe. La obra toma la forma de un coloquio entre Patricio, un ciudadano interesado en la buena educación cristiana de su familia, su hijo Ambrosio, que, en contra de lo habitual, está bien instruido en materias religiosas, y el padrino de éste, Dionisio, que representa los ideales erasmianos de una fe interior. Se explican el bautismo, la redención y justificación del pecador por el sacrificio de Cristo, el credo, los diez mandamientos, la dependencia total de la misericordia de Dios. Se habla de la eficacia y las condiciones de la oración que se debe hacer con recogimiento y humildad y en espíritu. Aparte del bautismo, otros sacramentos son el de la penitencia, de la comunión y de la misa. Ponce realza la importancia de una buena predicación, sencilla, inteligible e instructora. La obra termina con la traducción del Sermón en la Montaña.

El Catecismo cristiano (Sevilla 1547) ${ }^{17}$ es grosso modo un resumen de la Suma, pensado para niños, y de ahí más sencillo. Podría ser la base para la instrucción

$9 \quad$ F. Álvarez, "El movimiento bíblico en Sevilla durante el siglo XVI", en Archivo Hispalense, 26, 1957, pp. 9-45, aquí pp. 32 ss. y p. 30.

10 Detalles en E. Schäfer, op. cit., pp. 271-272.

11 Así lo supone T. M'Crie, op. cit., p. 273.

12 Para los detalles ‘folklóricos' de este auto cf. R. González Montes, Algunas artes de la Santa Inquisición Española, descubiertas y hechas públicas, ed. F. Ruiz de Pablos, Madrid, Universidad nacional de educación a distancia, 1997, pp. 284 ss. y pp. 306 ss.; y T. M'Crie, op. cit., pp. 275-276.

13 R. González Montes, op. cit., pp. 342 ss.

14 Ibidem, p. 347.

15 C. Ponce de la Fuente, op. cit., pp. 1-274.

16 C. Ponce de la Fuente, Doctrina Christiana, en que está comprehendida toda la información que pertenece al hombre que quiere servir a Dios, Sevilla, 1548. No se tratará aquí por estar inacabada y por no aportar nuevos aspectos socio-culturales o históricos comparado con la Suma.

17 C. Ponce de la Fuente, Catecismo christiano, Compuesto por el Doctor Constantino. Añadiose la confession d'vn pecador penitente, hecha por el mismo Author, Amberes, 1556. (Primera publicación: Sevilla, 1547.), en C. Ponce de la Fuente, Suma, op. cit., pp. 279-358. 
de Ambrosio de la Suma, pero al parecer se escribió posteriormente como una síntesis. Se explican el credo, los mandamientos, la oración, los sacramentos - que en esta obra solo comprenden bautismo, penitencia y comunión-, la misa y la predicación.

Otras obras de Ponce de instrucción reformada general son el Sermón del Monte ${ }^{18}$ (Sevilla 1543), que es una breve esencia de doctrina reformada, compuesto por el orden tradicional (exordio, narratio, confirmatio y epilogus), una exposición sobre el primer Salmo y la Confesión de un pecador ${ }^{19}$ (Sevilla 1547; tal vez existiera una edición anterior), llena de reminiscencias de Lutero. La contrición de un pecador debe ser absoluta dado que depende completamente de la misericordia de Dios y de la redención por Cristo. Las explicaciones sobre los pecados contra los mandamientos y el credo corresponden a lo expuesto en tratados anteriores.

A la Suma el autor añade dos Epístolas de San Bernardo, De la perfección de la $v i d a^{20}$, que amonesta a los ejercicios de penitencia y al desprecio las cosas del mundo, y la Epistola silvestre ${ }^{21}$, traducida por el canónigo de Sevilla Martín Navarro, amigo de Ponce. Predica la moderación, la diligencia y el buen comportamiento con los demás. Estas cartas contienen más bien consejos prácticos, sin pretensiones teológicas. Son, por lo tanto, inofensivos. Solo la mención final "I elije, por curadór de tu ánima, a persona, que sepas, que tiene cargo de la suya"22 puede reflejar la crítica de Ponce hacia los curas inmorales ${ }^{23}$. El traductor de esta carta, el canónigo de Sevilla Martín Navarro, era amigo de Ponce.

Ponce es encarcelado cuando se detectan manuscritos suyos con explicaciones de los conflictos entre las Iglesias, que iban a ser el segundo tomo de su Doctrina cristiana. Eran tratados sobre el estado de la Iglesia, el Papa, la eucaristía, la misa, la justificación, el purgatorio, las bulas e indulgencias y la vanidad de las obras ${ }^{24}$, títulos que muestran ya de por sí la fuerza explosiva temática.

18 C. Ponce de la Fuente, Sermón del Monte. El Sermón que nuestro Señór Jesu Cristo hizo en el monte. Traduzido en castellano por el doctór Constantino, Sevilla, 1551. (Primera publicación, probablemente Sevilla, 1543), en C. Ponce de la Fuente, Suma, op. cit., pp. 238-274.

19 C. Ponce de la Fuente, Confesión de un pecador. Confesión de un pecadór, delante de Jesucristo redemptór, $i$ juez de los hombres. La cual servirá para exhortár, a cualquiér otro pecadór, a verdadera penitenzia, i darle doctrina de muchas consideraziones, azerca del conoszimiento de si mismo, i de lo que debe a Dios, $i$ de como ha de invocár la misericordia Divina siguiendo, en todo, por luz, i por regla, lo que para cada cosa d'estas, la Sancta Scriptura nos tiene enseñado. Amberes 1556. (Primera publicación: Sevilla, 1547). Aquí se utiliza la edición más reciente, con una introducción de David Estrada y texto actualizado por Emilio Monjo Bellido: C. Ponce de la Fuente, Exposición del primer salmo de David. Confesión de un pecador, Alcalá de Guadaíra, Eduforma, 2009.

20 C. Ponce de la Fuente, Suma, op. cit., pp. 393-397.

21 Ibidem, pp. 400-409.

22 Ibidem, p. 409.

23 Acerca del anticlericalismo como motor de la Reforma, cf. P. Blickle, "Neuorientierung der Reformationsforschung?”, en Historische Zeitschrift 262/2, 1996, pp. 481-491, aquí 482. En el mismo artículo, p. 482, Blickle critica a Hans-Jürgen Goertz que ve en el odio hacia los curas ("Pfaffenhass") el inicio del proceso reformatorio. Cf. H.-J. Goertz, Antiklerikalismus und Reformation. Sozialgeschichtliche Untersuchungen, Göttingen, Vandenhoeck \& Ruprecht, 1995, p. 116.

24 F. Álvarez, op. cit., p. 36. 


\section{Motivos y géneros literarios}

Se observa que las obras escritas en forma de ensayo o tratado teológico, tanto del exiliado interior Ponce como de autores protestantes castellanos que escriben en el extranjero, se limitan en gran parte a exponer doctrinas. El Catecismo y la Confesión de un pecador son obras cuyo fin es principalmente doctrinal. Sirven para evangelizar e instruir y no contienen pretensiones políticas. Sin embargo, en muchos casos sus omisiones y los encubrimientos son significativos, como veremos más adelante.

En la época de las Reformas, la explicación de doctrinas toma con frecuencia la forma predilecta de los escritos dialécticos. En su escrito principal, Suma de doctrina cristiana, Ponce contrasta, también de forma dialéctica, cada punto teológico con los dogmas católico-romanos. Sus motivos principales son, también aquí, la evangelización y la instrucción teológica. Aparte de alguna ironía fina, sus textos son en gran parte libres de polémica.

En muchas obras de escritores protestantes hispanos, los prefacios, dedicatorias, subtítulos y citas bíblicas, o la publicación de textos álibi - de indudable ortodoxia - junto con el propio, son un proceder habitual para legitimar los textos y convencer de sus contenidos. La Suma de Doctrina cristiana, dedicada al que fuera arzobispo de Sevilla, presidente del Consejo del Rey y futuro Inquisidor General, el cardenal Francisco García de Loaysa ${ }^{25}$, encontró al principio buena acogida entre teólogos de varias orientaciones dogmáticas. La dedicatoria pone énfasis en la catolicidad de la obra: "se escribió señaladamente para la iglesia, cuyo Prelado i Pastór es Vuestra Señoría" ${ }^{26}$. Subraya el daño moral y espiritual que una falsa doctrina puede producir en la gente y la importancia de que los súbditos estén enterados de que la obra haya sido autorizada por Loaysa. Ponce presenta su doctrina como sencilla, "para gente sin erudizión i letras"27. A la dedicatoria sigue una advertencia Al Lectór Christiano, donde el autor intenta dar aún más legitimidad al texto: algunos amigos le han pedido publicar esta Suma; la mayoría de las obras existentes de este género no enseñan la verdadera religión - ¡afirmación bastante atrevida! - . Ponce sostiene que el contenido del texto corresponde a la doctrina de la Iglesia católica (sin añadir romana); escribir tales instrucciones es una tarea mandada por las autoridades eclesiásticas ${ }^{28}$.

El disimulo de Ponce se manifiesta, aparte del contenido, en otro artificio para otorgar a un texto más credibilidad ante la ortodoxia romana. En la edición de sus escritos incluye los ya mencionados textos de San Bernardo o escritos de Luis de Granada: obras álibi de indudable integridad dogmática que salvan las apariencias ortodoxas romanas

Su Catecismo cristiano lo dedica a otro amigo, el obispo de León y canónigo de la catedral de Sevilla, además de asistente del Concilio de Trento, Juan Fernández

25 En una carta del 8 de junio de 1532, Loaysa recomienda a Carlos V admitir la libertad de culto para obtener ayuda contra los turcos y especifica que el Emperador puede tener la conciencia limpia ante el Papa, aunque no ante Dios. La carta está reproducida en J. Pérez de Pineda, Suplicación a Don Felipe II. Suplicazion a la Magestad del Catholico Rei Don Philipe etc., s.1. (¿Ginebra?) 1559, en F. de Enzinas, Dos informaziones, J. Pérez de Pineda, Suplicazión a Don Felipe II, San Sebastián, 1857, reimpreso Barcelona, Librería de Diego Gómez Flores, 1982 (es el tomo XII de la serie Reformistas Antiguos Españoles), pp. 1-43 y pp. 55-57 de las anotaciones.

26 C. Ponce de la Fuente, Suma, op. cit., hoja II.

27 Ibidem, hoja III.

28 Ibidem, hoja III/IV. 
Temiño, quien, como se apresura Ponce en afirmar, siempre se ha empeñado en instruir bien a los feligreses y quien, a este fin, le ha pedido escribir el librito, proyecto que nunca ha sido tan importante como ahora ${ }^{29}$.

\section{Lenguaje y estilo}

Hemos dicho que Ponce no es un escritor que destaque por un tono polémico. Sin embargo, tal vez formule acusaciones indirectas cuando en la Suma, en la exposición del octavo mandamiento, habla de "mentirosos", "hipócritas" o "vanagloriosos"30. puede referirse al clero, por más que poco después arremete contra los predicadores falsos e hipócritas ${ }^{31}$, después de haber lamentado, comentando el séptimo mandamiento, la existencia de prelados que emplean mal el dinero y de personas que no son dignas de ser ministros de la Iglesia ${ }^{32}$.

En sus escritos, en cambio, son elocuentes los silencios: en el Catecismo no se menciona ni una vez al Papa; en la Suma de doctrina cristiana, con respecto a la cuestión de los sacramentos, remite a una obra que tenía previsto escribir más adelante ${ }^{33}$. En este contexto es necesario tener en cuenta que el disimulo - el nicodemis$m o^{34}$ - era imprescindible para la autoprotección de muchos autores, sobre todo los que se quedaban en aquellos territorios de la Monarquía hispana donde la Reforma había causado poco impacto, a saber, la Península Ibérica e Italia ${ }^{35}$.

Ponce es un maestro en este arte del disimulo, por lo menos en las obras que han llegado hasta nosotros; si se da crédito a las Artes de Montes, había escrito obras donde se explicaba con bastante más franqueza: En De la verdadera Iglesia y de la Iglesia del Papa llamaba Anticristo al Pontífice; en Del sacramento de la Eucaristía $y$ del invento de la Misa afirmaba que el orbe estaba fascinado por la ignorancia de la Sagrada Escritura; y en Del Purgatorio opinaba que éste era cabeza de lobo e invento de frailes para llenar su vientre ${ }^{36}$.

Sabe insinuar sus ideas teológicas sin hacer reivindicaciones abiertas de protestantismo o críticas explícitas. En la Suma de doctrina cristiana, a través de Dionisio, su alter ego, opina que hay que entender lo que está detrás de las ceremonias, sin exigir su abolición, como lo hacen muchos de nuestros autores ${ }^{37}$. La fe sin obras es muerta, la verdadera fe es la que engendra las obras ${ }^{38}$ — ¡nada sobre las críticas reformadoras de la eficacia ex opere operato!- Afirma que pecan los que no

\footnotetext{
C. Ponce de la Fuente, Catecismo, op. cit., p. 279 ss.

C. Ponce de la Fuente, Suma, op. cit., p. 138.

Ibidem, pp. 138-139 y p. 231.

Ibidem, p. 131.

Ibidem, p. 215.

"La calificación de "nicodemita" fue ideada por Calvino con un sentido peyorativo. Nicodemita es el hipócrita que, por temor al martirio (...) no confiesa ante los demás la fe regenerada o reformada que profesa.” J. Biedma López, El nicodemismo de Juan de Valdés, http://www.iglesiareformada.com/Lopez_Nicodemismo.html (consultado 29 junio 2016).

35 Acerca de la influencia del nicodemismo de J. de Valdés sobre Ponce cf. también J. C. Nieto, “Juan de Valdés sobre la catequesis”, en Juan de Valdés y los orígenes de la Reforma en España e Italia, Madrid, FCE, 1979, pp. 603-623, aquí p. 614.

36 R. González de Montes, op. cit., p. 350.

37 C. Ponce de la Fuente, Suma, op. cit., p. 1 ss.

38 Ibidem, p. 29.
} 
aceptan el sacrificio de Cristo y confían en otros medios para conseguir el perdón ${ }^{39}$. Solo en Dios hay que buscar remedio ${ }^{40}$. Él solo puede dar "Carta de libertád" de los pecados ${ }^{41}$. Aquí especialmente vemos cuán discreto es el proceder de Ponce, que no arremete contra las bulas e indulgencias.

Con respecto al noveno artículo del credo, creer en la Iglesia católica y santa, explica que la Iglesia es "católica", universal, pero consiente que excluye las congregaciones cismáticas y heréticas (sin concretarlas) ${ }^{42}$. La misma aparente ortodoxia la encontramos en el Catecismo cristiano:

Llamamos a esta Iglesia, 'Sancta'; porque por su fé, i sus obras, son todos los miembros d'ella, azeptos á Dios, i juntados con Él, en grandísima amistad. Llámase 'Cathólica', porque donde quiera que estén los tales miembros, son miembros de un mismo cuerpo místico, i espiritual, cuya cabeza es Cristo, nuestro Redemptór. Con el cuál están (...) unidos con una misma fé, i una misma caridád, sin que errór, ni herejía, los divida entre sít ${ }^{43}$.

En esta obra trata "sino de los mas prinzipales" 44 sacramentos: bautismo, penitencia y comunión. Con esta formulación vaga no se compromete acerca de lo que considera un sacramento.

Hablando del artículo de la comunión de los santos, del credo, critica al que "quisiere para sí solo, la sanctidád" ${ }^{45}$; bien se puede aquí referir a las pretensiones de monjes o sacerdotes de tener un status especial.

Para la santa comunión hace falta un ministro "zeloso de Dios, que tenga bién entendida la zertinidád de la doctrina, i el fín, para que nuestro Redemptór instituyó este misterio" ${ }^{46}$. Esto parece a primera vista conforme con la doctrina católico-romana, pero no la especifica como tal y nos deja en la incertidumbre sobre lo que él entiende por doctrina.

Explica por qué incluye en la Suma el Sermón de la montaña: "para que se vea la conformidád de lo que él contiene, con la doctrina del Redemptór, i que sea ella el exámen, i la prueba, la declarazion, i la luz, de todo lo que los hombres dijeren" ${ }^{47}$. Sin rodeos esto significa el sola scriptura de los reformados. Que Ponce oculte una actitud anti-eclesiástica se corrobora por sus críticas de los escribas y fariseos que arremetían contra Cristo, que enseñaba la pureza de la Escritura ${ }^{48}$. Termina avisando que seguir a Cristo es meterse en peligros como él, Ponce, lo hizo ${ }^{49}$.

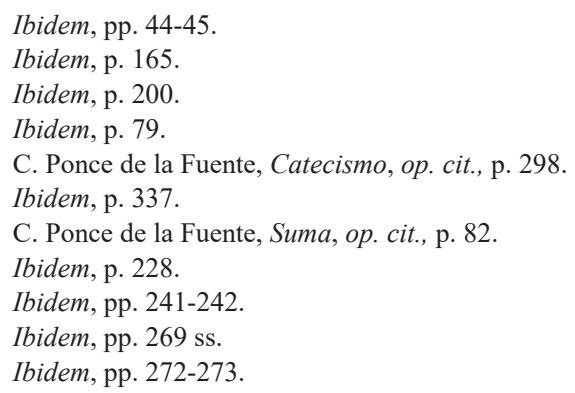




\section{El programa reformatorio}

La reforma luterana, iniciada en 1517, propagaba principalmente la justificación por la sola fe en vez de por los méritos humanos, negaba la autoridad del Papa y de las Tradiciones, el culto a la virgen y a los santos, el valor de las indulgencias y la existencia del purgatorio; pregonaba la lectura de las Sagradas Escrituras en lengua vernácula y criticaba la jerarquía eclesiástica y las órdenes monásticas.

Las doctrinas protestantes de Constantino Ponce de la Fuente, por presentarse de forma camuflada, quedan a primera vista algo nebulosas, debida a la precaución necesaria en sus textos, a fin de no tropezar con la censura inquisitorial ${ }^{50}$. Sin embargo, a pesar de la cautela, la Suma de doctrina cristiana fue calificada como alumbrada por la censura; también se criticó que había silenciado aspectos importantes como el Papado, y descalificado otros, como la existencia del purgatorio y la importancia de los méritos para la salvación ${ }^{51}$. Este último es un reproche infundado: la Suma, donde se explica detalladamente la doctrina de la justificación —isin llamarla por su nombre! $!^{52}$ - sostiene que, a pesar de la ineficacia de los esfuerzos humanos para la salvación, las obras exteriores son frutos de las interiores y que, junto con las prácticas religiosas y la oración, son un apoyo a la fe; la fe acarrea las obras por el amor al prójimo ${ }^{53}$, Para Ponce, como para Valdés, la fe es muerta si no se acompaña por las obras. Como Erasmo, Alfonso de Valdés, Lutero y Calvino, Ponce defiende el ideal del cristiano laico viviendo conforme a los mandamientos divinos ${ }^{54}$. Su afirmación de que solo Dios puede perdonar los pecados implica que no los pueden remitir las bulas e indulgencias, aunque el autor apoya el poder de absolver de los sacerdotes ${ }^{55}$. Las buenas obras tienen que acompañar los rezos $^{56}$. Es recomendable la oración interior, con recogimiento, pocas palabras y sin ostentación ${ }^{57}$; si alguien no es capaz de ello es mejor no rezar otras oraciones que el Padrenuestro porque en ésta está todo dicho ${ }^{58}$.

En la Suma, Ponce considera sacramentos la confesión, la comunión y la misa ${ }^{59}$, sin que limite explícitamente su número a tres, una cautela que ya hemos visto en su Catecismo. En ambas obras presenta la misa como la viva representación de la muerte de Cristo; aquí se acerca a la posición católico-romana. La misa es la representación de la pasión y muerte de Cristo — si bien en memoria de su muerte—; su

50 Cf. J. C. Nieto, El Renacimiento y la otra España. Visión Cultural Socioespiritual, Ginebra, Librairie Droz, 1997, pp. 186-187. Se supone que Constantino hablara más claramente en sus predicaciones, y se sabe por Montes que atacó directamente muchos ritos y dogmas católico-romanos en una obra clandestina: R. González de Montes, op. cit., p. 350. Kamen niega luteranismo a Ponce y a Egidio: sostiene que no eran protestantes en realidad, sino humanistas a favor de una vida religiosa espiritual. Cf. H. Kamen, La Inquisición española. Nueva edición totalmente reescrita y puesta al día por el autor, Barcelona, Grijalbo, 1985, p. 104 y p. 110. Sobre el desarrollo de la censura de libros protestantes cf. A. G. Kinder, "Le livre", pp. 302 ss.

51 R. González de Montes, op. cit., pp. 352-353. Para paliar las acusaciones, Ponce remitió al segundo tomo de la Doctrina Cristiana que iba a redactar.

52 C. Ponce de la Fuente, Suma., op. cit., pp. 44 ss. y pp. 62-63.

53 Ibidem, pp. 154-155.

54 Ibidem, hoja VIII y p. 24, p. 29 y pp. 172 ss.

55 Ibidem, pp. 215-216.

56 Ibidem, pp. 172 ss.

57 Ibidem, pp. 166 ss.

58 Ibidem, pp. 210 ss.

$59 \quad$ Ibidem, pp. 215 ss. 
sacrificio se renueva en cada misa ${ }^{60}$. Esta posición es sorprendente dado que antes ya ha afirmado que Cristo sufrió para todos los pecados de todos los tiempos ${ }^{61}$, con lo que se expresa en contra de la misa como sacrificio.

Lamenta el conocimiento defectuoso de la doctrina cristiana y la insuficiencia de comprender las ceremonias para tener provecho de ellas ${ }^{62}$. Conviene leer los Evangelios en romance ${ }^{63}$. Con el mero cumplimiento de las exterioridades llevamos "una vida de fariseos, o falsos Christianos" $"$ y solo tenemos "aparienzia de Christiano" 65 . En todo este coloquio se critican las deficiencias en la enseñanza cristiana y se destaca la necesidad de una profunda educación ya en la tierna infancia. Ponce también impugna a los prelados que para cumplir con su cargo se limitan a encomendar sus obligaciones a otros ${ }^{66}$, y denuncia la hipocresía: los que oran y ayunan en público son una "pestilenzia de vanagloria"67.

Ponce critica solo implícitamente el culto mariano: en la explicación del tercer artículo del credo habla de la "virgen" sin llamarla santa ${ }^{68}$. El hecho de calificarla en el mismo contexto "cosa tan sancta" ${ }^{\circ}$ — y en el Catecismo "madre santísima"70 indica que no es su intención negar su santidad, sino que tan solo quiere evitar que sea adorada como Dios.

En la Suma, aunque por un lado describe la comunión como un memorial de la pasión de Cristo y como "spirituál manjár" de cuerpo y sangre de Jesús: “(...) i no representazión, así como quiera, sinó donde se halla el mismo cuerpo que fué enclavado en la cruz, i la misma sangre, que fué derramada (...)" 72 . Ponce parece defender la ubiquitas luterana, la consustancialidad de las dos especies en la Santa Cena.

En cuanto a la esencia de pan y vino de la Santa Cena, también en el Catecismo dice explícitamente que para los perdonados son el cuerpo y la sangre de Jesucristo ${ }^{73}$. Posteriormente, especifica que el fiel "Debe de considerar, que están, allí, el cuerpo, i la sangre del Redemptór i la memoria de su Pasión (...)" "74. Como todos los autores, Ponce subraya la necesidad de ofrecer la comunión bajo las dos especies ${ }^{75}$. Aquí y en la Suma recomienda celebrar la comunión con frecuencia ${ }^{76}$.

Con todo, no se expresa muy en concreto sobre las prácticas católico-romanas. Con la ambigüedad que le es propia, en el contexto del credo, tal vez aluda al culto de las reliquias en forma de juego de palabras, admitiendo al mismo tiempo otra

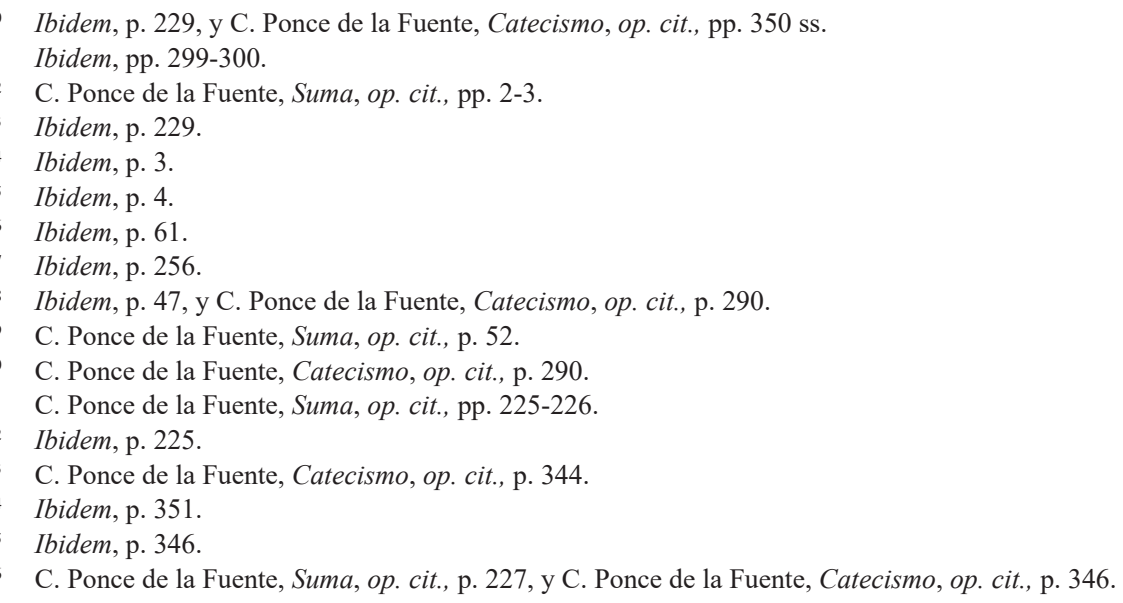


interpretación que se refiere solo a las reminiscencias del pecado: "desechemos, en todo, las reliquias, i condiziones, del viejo pecado (...)" "77. Por lo demás, se limita a acusar supersticiones y hechicería ${ }^{78}$.

La tercera obra de Ponce aquí tratada y según Montes su mejor obra ${ }^{79}$, la Confesión de un pecador, también trata de la justificación por la fe, que tampoco aquí se nombra directamente ${ }^{80}$. "Descendiste a ser hombre, y hombre nuevo, del mismo linaje de Adán pero sin culpas de Adán, porque así convenía a tu grandeza y convenía a nuestra justicia" ${ }^{11}$. Las obras no tienen ningún valor redentor:

Con tan grandes ceguedades y tan grandes ignorancias de ti y de mí, con tan gran olvido de tus bienes (...), mis arrepentimientos no podían ser sino falsos, dorados con oro falso, llevados del primer viento $(\ldots)^{82}$.

Acuérdate de mí, Señor, ya que estás en tu reino. Para mi justicia no tengo qué alegar, sólo conocer cuán injusto soy. Para moverte nada tengo sino que veas mis grandes miserias. Derecho al remedio de tu mano no tengo, sino otro remedio pretender. No hay otro sacrificio de mi parte sino mi espíritu atribulado y mi corazón afligido ${ }^{83}$.

Los puntos dogmáticos tratados nos llevan a la pregunta sobre la afiliación de Ponce a una confesión determinada. No es fácil reconocer la identificación con alguna confesión determinada. Debido a la escasez de literatura dogmática reformada en territorios hispanos, se desarrolló aquí un sincretismo de las variantes del protestantismo, que solo en el caso de los exiliados pudo evolucionar hacia una confesión concreta. En palabras de Kinder:

Es verdad que en España no eran demasiado bien conocidas las variedades nacionales y confesionales del protestantismo, lo que produjo un protestantismo que no era exactamente semejante a lo que había evolucionado en uno u otro país del norte de Europa, y resultó algo desconcertante para ciertos refugiados cuando llegaron a países reformados ${ }^{84}$.

El sincretismo protestante de Ponce se forma tanto dentro del territorio hispano como en el extranjero, durante su viaje con el emperador ${ }^{85}$. La acusación principal contra él será la de mantener el dogma de la justificación, a pesar de sus precauciones a la hora de explicarlo.

Ibidem, p. 291. El subrayado es nuestro.

Ibidem, p. 304.

R. González de Montes, op. cit., p. 253.

C. Ponce de la Fuente, Confesión, op. cit., pp. 307-308.

Ibidem, p. 307.

Ibidem, p. 310.

Ibidem, p. 313.

${ }^{84}$ A. G. Kinder, "Los monjes de San Isidoro del Campo: Reina-Valera y la Biblia del Oso", manuscrito de una conferencia pronunciada durante los cursos de otoño de la Universidad de Sevilla, 1990, p. 3.

85 Esto desmiente la afirmación de M. Bataillon, op. cit., p. 517, de que "su religión, salvo error, tiene sus raíces en la misma España, en el iluminismo erasmista. El caso de estos eclesiásticos, que desempeñaron en su país un papel importante o glorioso antes de ser encarcelados a causa de su «luteranismo», no difiere esencialmente, en el fondo, del caso de un Juan de Valdés". 
Una característica de la identidad religiosa de los autores protestantes hispanos en general, y de Ponce en concreto, es el énfasis que ponen en la larga tradición de su fe, la "vieja doctrina" para ellos, que debería ser la universal: la verdadera fe católica, aunque no romana, frente a la cual los dogmas romanos constituyen una perversión posterior del cristianismo ${ }^{86}$. Esta argumentación se encuentra en la misma línea de la primera gran historia eclesiástica protestante, las Centurias de Magdeburgo (Basilea 1559-1574), del luterano Matthias Flaccius Illyricus, cuyos 13 volúmenes intentan, por medio de una investigación crítica, hacer constar las usurpaciones doctrinales posteriores por parte del catolicismo romano y la corrupción de la tradición ${ }^{87}$.

También Ponce de la Fuente quiere demostrar que sus dogmas reflejan el cristianismo auténtico tal y como se propagó por los apóstoles en los inicios del cristianismo. En el aviso Al lector cristiano que precede la Suma, aclara sus creencias:

Esta doctrina (...), es la que la Iglesia Católica en su prinzipio enseñó, con grandísimo cuidado, a sus hijos. Esta era la predicazión de estónzes: i lo que en las públicas, i particulares Congregaziones se tractaba, del negozio de Jesu Christo Redemptór, i Señór del mundo. Aquí está sumado, i recolejido, todo lo que está sembrado por las Scripturas Divinas (...). El demonio introdujo doctrinas falsas, adversidades vinieron por estos pecados $(\ldots)^{88}$.

Más adelante afirma en el mismo prefacio que "Siempre le es cosa áspera, i escandalosa [al mundo], dezirle, que vuelva á la virtúd antigua" ${ }^{29}$. El Catecismo define la Iglesia católica como el "conjunto de los fieles en todo el mundo" y la "comunión de los santos"90.

En la literatura religiosa de la época es frecuente la idea de que las calamidades sufridas, tanto las políticas - por ejemplo, las guerras turcas - como las religiosas, sean un castigo de Dios quien a través de ellas quiere mostrar el camino recto a la humanidad ${ }^{91}$.

En la advertencia al lector de la Suma, Ponce de la Fuente lamenta las "grandes adversidades, que han venido a la Christiandád por nuestros grandes pecados: las zeguedades, que ha procurado en introduzír en ella el Demonio: la variedad de doctrinas (...)." "92 y las "porfías", y la "confusión y tinieblas" ${ }^{93}$, sin precisar a quien se refiere. Sin embargo, poco después advierte que deberíamos tomar como ejemplos a los "Antiguos" 94 que no abandonaron el verdadero cristianismo. Puede ser una alusión a un tiempo anterior a la Iglesia de Roma y encaja bien en la costumbre refor-

86 C. Ponce de la Fuente, Suma, op. cit., p. 79.

87 Cf. también J. L. de Orella Unzué, Respuestas católicas a las Centurias de Magdeburgo (1559-1588), Madrid, Fundación, 1976, passim. En 1567 A. del Corro tiene divergencias con Flacius Ilyricus (que es latitudinario) acerca de la comunión, que Flacius entiende como presencia real de Cristo. Cf. E. Boehmer, Bibliotheca Wiffeniana. Spanish Reformers of two Centuries from 1520. Their lives and writings, according to the late Benjamin $B$. Wiffen's plan and with the use of his materials, 3 vols., Estrasburgo/Londres, Trübner, 1874/1883/1904, t. III, Estrasburgo 1904, pp. 21 ss. Flacius también se había enemistado con Lutero.

88 C. Ponce de la Fuente, Suma, op. cit., hoja IV.

89 Ibidem, hoja V.

90 C. Ponce de la Fuente, Catecismo, op. cit., pp. 298-299.

91 C. Ponce de la Fuente, Suma, op. cit., pp. 204-205.

92 Ibidem, hoja IV.

93 Ibidem, hoja IV.

94 Ibidem, hoja IV. 
mista de referirse al protestantismo como la tradición antigua. Así, en última consecuencia, la razón por la que Dios impone su castigo es haber abrazado la fe romana.

\section{Implicaciones políticas}

A pesar de las severas críticas hacia la Iglesia romana y su cabeza, entre los pensadores de la época no faltan corrientes que trasladan la idea de la universalidad del poder desde el emperador al Papa: no solo la Iglesia, sino también los temporalia han sido confiados al Pontífice ${ }^{95}$. El ideal de una variedad de Estados nacionales, rival de los dos pretendientes al poder universal, cuenta ya con adeptos desde mediados del siglo $\mathrm{XIV}^{96}$. En la época que aquí nos interesa, el trinitario Alonso de Castrillo, adversario decidido de la Weltanschauung de corte carolino, se refiere al constitucionalismo medieval cuando, en su Tractado de República (publicado en 1521), destaca tanto la obligación del pueblo de impedir que el rey cometa acciones nocivas como la conveniencia de limitar las prerrogativas de un príncipe a un solo dominio. Sin embargo, Castrillo va menos lejos que los Comuneros, que sostienen que después de incurrir en un error, la soberanía recae sobre el pueblo ${ }^{97}$.

Estos debates en torno a la legitimidad de las autoridades entran también en las disputas de la Reforma. En estrecha relación con las crisis de la centuria se reanuda, en España como en toda Europa, el viejo debate acerca de la obligación de obedecer a las autoridades, tan defendida en un principio por la doctrina luterana, para desarrollar más tarde unas teorías a favor de una guerra justa, de procedencia agustiniana, y el derecho a la resistencia. Tanto la Apología escrita por el hugonote Pierre Loyseleur de Villiers, como el Edicto de los Estados Generales de las Provincias Unidas, ambos publicados en 1581, reproducen la afirmación de Guillermo de Orange de que la resistencia de los magistrados inferiores, frente a los superiores, no solo es un derecho, sino un deber ${ }^{98}$.

Francisco de Vitoria, titular de la primera cátedra de teología en Salamanca y participante de la Asamblea de Valladolid que discute las obras de Erasmo, adopta el concepto ockhamista y luterano de la separación del gobierno eclesiástico y el temporal (Zwei-Reiche-Lehre luterana). Vitoria se acerca a los pensadores protestantes admitiendo que el poder del soberano nunca es mayor que el del pueblo que se lo concedió. En De potestate civili (1528) afirma que toda potestad legítima viene de Dios y es, como la sociedad misma, de derecho natural y divino. Defiende la guerra justa argumentando con el derecho a la autodefensa que incumbe también al Estado. Más tarde, y en la misma línea ockhamista, el jesuita Francisco de Suárez defenderá la soberanía popular y el derecho, por parte de los súbditos, de revocar

95 Acerca del concepto de la Universitas, cf. P. Fernández Albaladejo, Fragmentos de monarquía, Madrid, Alianza Universidad, 1992, pp. 60 ss. Sostiene que la idea de una cabeza temporal de la Universitas christiana persistiera en el siglo XVI.

96 Cf. K. O. von Aretin, "Lutero y las repercusiones de la Reforma en la política europea", en J. Belloch Zimmermann, A. Rodríguez Sánchez (eds.), Lutero y Reforma. Simposio de la Universidad de Extremadura sobre Martín Lutero (1483-1546), Cáceres, Universidad de Extremadura, 1985, pp. 87-99, aquí pp. 88-89.

97 Sobre las ideas políticas de Castrillo, cf. J. A. Fernández-Santamaría, The State, War and Peace. Spanish Political Thought in the Renaissance 1516-1559, Cambridge, Cambridge University Press, 1977, pp. 14 ss.

98 Acerca de la resistencia en el pensamiento protestante, cf. Q. Skinner, Los fundamentos del pensamiento político moderno, 2 vols., México, Fondo de Cultura Económica, 1985/86, pp. 18ss., pp. 72ss., pp. 88ss., y pp. 197ss. 
el contrato que hicieron con el gobernante, y de ofrecerle resistencia si lo incumple (De legibus ac Deo legislatore, 1613). El dominico Domingo de Soto, profesor de Salamanca y Alcalá, consultor del emperador y participante de la Asamblea de Valladolid y del Concilio de Trento, había afirmado, en líneas generales, lo mismo (De iustitia et iure, 1557) ${ }^{99}$.

En la Suma de doctrina cristiana, por lo demás una obra con pocas implicaciones políticas, encontramos el argumento del respeto hacia las autoridades como voluntad de Dios. El cuarto mandamiento incluye también la obediencia hacia las autoridades. Lo expone Ambrosio:

En el cuarto Mandamiento, comienza la segunda Tabla, en la cuál, el hombre es enseñado, en cómo se ha de habér, con los otros hombres. (...) I, porque lo prinzipál, que entre los hombres conserva la paz, i el orden, que Dios les ha puesto, es la obediencia, i sin esta, ningún otro bién podría tenér lugar; comienza a tratár, d'ella, el cuarto Mandamiento $(\ldots)^{100}$.

Dionisio le pregunta si "este Mandamiento se extiende a otras personas algunas,

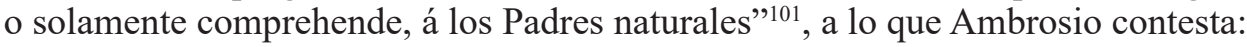

Como este Mandamiento sea de obediencia, i no de cualquier obediencia, sinó de aquella, que es menester, para conservar el conzierto, i paz, que Dios tiene puesta, i pide, que haya entre los hombres; claro está que se extenderá, a todos aquellos, que, para este fin, son superiores, i como padres. I así habemos de entender, que en este Mandamiento, está mandado, que honrremos, i obedezcamos, a nuestros superiores todos. Que los vasallos, obedezcan a sus Reyes, a sus Señores, a sus Ministros, i a sus Justizias (...). Porque, todos estos, tienen razón, i ofizio de padres, para con los otros. Los Prínzipes i Ministros de la Justizia, nos substentan en paz, i en concordia: (...) el Señor, es como padre de su familia: i así se puede ir discurriendo, por todos los demás. I, por esto, no solo se les debe honrra, i acatamiento de exteriores ceremonias, mas también de lengua, de comedimiento, de reconoszér la superioridad, i ventaja, que Dios les quiso dár: de no perseguir, e infamar sus faltas, si algunas les conosziéremos: de tener respecto, i estima, al ofizio, i cargo que tienen ${ }^{102}$.

De la última frase se desprende que, respetando las autoridades, se respeta en ellas no la persona, sino el cargo que les ha sido asignado por Dios. Lo confirma Dionisio poco después:

Porque, cuando se dize, que el hijo honrre, i obedezca al padre; entiéndese, que es por razón del ofizio, que el padre tiene con el hijo (...). I, en pedir al súbdito que obedezca, i honrre al Perlado, se le dá a entender al Perlado, los dones, que ha de tenér, para ser Perlado.(...) Por este mismo camino, se le pide al Prinzipe lo que se

\footnotetext{
99 Sobre los pensamientos políticos de Soto y Vitoria cf. M. Andrés Martín, La teología española en el siglo XVI, 2 vols., Madrid, Biblioteca de Autores Cristinanos, 1976, t. II, pp. 481 ss.; sobre Vitoria: J. A. Fernández-Santamaría, op. cit., pp. 58 ss. y pp. 97 ss.

100 C. Ponce de la Fuente, Suma, op. cit., p. 109.

101 Ibidem, p. 110.

102 Ibidem, pp. 110-111.
} 
requiere, para el gobierno, para la justicia, i la paz de sus vasallos. I, al Ministro de la justizia, la szienzia, i guarda de las Leyes $(. . .)^{103}$.

Por esta misma razón, es decir el carácter divino del poder, los superiores también tienen obligaciones hacia sus súbditos. Es cierto que Ponce, como Lutero ${ }^{104}$, ve en los tiranos un instrumento divino para castigar las maldades del pueblo; Dionisio afirma que debemos reconocer que,

si faltas hai en ellos; nuestros pecados, i ofensas, han mereszido, que no los tengamos mejores: i sufrirlos, en pazienzia, como la cruz puesta por mano del Señór, sobre nuestros hombros, para aviso, i castigo, de nuestras maldades ${ }^{105}$.

Asimismo deja claro que los "sediziosos, i alborotadores" pecan contra los preceptos divinos ${ }^{106}$. Sin embargo, poco antes ha afirmado que la condición de superior está vinculada al cumplimiento de las obligaciones que se derivan del cuarto mandamiento:

Porque, todos estos, son ministros de su Providenzia, [mándasenos] los obedezcamos, hasta en tanto, que manden, cosa contra el servicio suyo. Porque, en mandando esto, luego dejan de ser sus ministros. Donde mas claramente se entiende, cuánto quiere Dios, que los honrremos, cuando no mandan, cosa contra su servicio ${ }^{107}$.

Esto implica que, en este caso, la resistencia contra el mal gobernador si no es legítima al menos no ofende la voluntad de Dios.

En el Catecismo Ponce toca el tema de las autoridades solo de paso, también en el contexto del cuarto mandamiento; vuelve a afirmar que hay que honrar a padres y superiores. Sin embargo, también aquí encontramos un indicio de que el respeto hacia los superiores se condiciona por el comportamiento adecuado de éstos: "Cúmplese este Mandamiento, (...) cuando los [i.e. los padres] obedeziéremos en todas las cosas justas (...)"108.

Resumiendo, el análisis de los textos de Ponce nos permite obtener nuevos entendimientos en los campos literario, social y político. Sus tratados, muy estructurados, se limitan en gran parte a un contenido meramente teológico. Como muchos de sus correligionarios - y de sus adversarios del otro campo confesional - emplea también la forma dialéctica para contrastar opiniones teológicas, enfrentando directamente los puntos antitéticos, sin los intermediarios de una conversación ficticia, frecuentes en los escritores exiliados como Pérez de Pineda, Juan de Valdés y Cipriano de Valera. Como éstos y otros, Ponce busca legitimar sus escritos dedicándolos a gente fuera de duda dogmática, aduciéndola como instigadores de la obra o incluyendo el texto de una tal persona íntegra en la edición de la obra. Otro argumento

103 Ibidem, p. 114.

104 M. Lutero, "Si los hombres de armas también pueden estar en gracia" (1526), en J. Abellán (ed.), Martín Lutero. Escritos políticos, Madrid, Tecnos, 1986, pp. 128-170, aquí pp. 143-144. Tyndale tenía la misma opinión, cf. Q. Skinner, op. cit., pp. 77-78. 
legitimador de gran peso es el mayor grado de antigüedad y de originalidad de las creencias protestantes, comparadas con el catolicismo romano. Siempre procediendo con la debida prudencia, el autor está también en la línea de sus correligionarios cuando, por un lado, se declara leal a las autoridades y ve en las calamidades sufridas la voluntad de Dios quien castiga a la Cristiandad por haberse alejado de las verdades evangélicas, y por otro lado, cuando insinúa la posibilidad de resistencia en el caso de gobernadores que actúan en contra de la voluntad de Dios.

Vemos que Ponce se expresa al mismo tiempo con audacia y cautela. Su atrevimiento es consecuencia de sus convicciones religiosas, peligrosas en el territorio de la Monarquía hispana de la época y difícil de comunicar en un mercado literario estrictamente censurado. Sin embargo, la precaución con la que maneja los temas dogmáticos y políticos le permite hasta cierto punto expresarlas, aún en este complejo ámbito, al lector que esté dispuesto a leer entre líneas. 